\title{
Article \\ Effect of Three-Week Vibrotherapy on Selected Skin Parameters of Thighs and Buttocks in Women with Cellulite
}

\author{
Anna Piotrowska *(D) and Olga Czerwińska-Ledwig
}

Institute of Basic Sciences, Faculty of Physiotherapy, University of Physical Education, 31-571 Krakow, Poland; olga.czerwinska@awf.krakow.pl

* Correspondence: anna.piotrowska@awf.krakow.pl

check for

updates

Citation: Piotrowska, A.;

Czerwińska-Ledwig, O. Effect of

Three-Week Vibrotherapy on Selected

Skin Parameters of Thighs and

Buttocks in Women with Cellulite.

Cosmetics 2022, 9, 16. https:/ /

doi.org/10.3390/cosmetics9010016

Academic Editor: Enzo Berardesca

Received: 28 December 2021

Accepted: 24 January 2022

Published: 26 January 2022

Publisher's Note: MDPI stays neutral with regard to jurisdictional claims in published maps and institutional affiliations.

Copyright: (C) 2022 by the authors. Licensee MDPI, Basel, Switzerland. This article is an open access article distributed under the terms and conditions of the Creative Commons Attribution (CC BY) license (https:// creativecommons.org/licenses/by/ $4.0 /)$.

\begin{abstract}
Background: Cellulite (gynoid lipodystrophy, panniculopathy) affects approximately 85\% of women and is related to genetic and hormonal factors, diet, and low physical activity. Vibrotherapy is a promising method of physical therapy to help fight cellulite that has not been studied exhaustively yet. Materials and Methods: Sixty healthy women (age: 19-43 years) with cellulite of at least grade I on the Nurnberg-Muller scale were recruited. The participants were randomly assigned to four groups, receiving a series of 15 vibration treatments in a sitting or lying position for 30 or $60 \mathrm{~min}$. Before and after the first and last treatment, selected skin parameters were measured with the use of Courage and Khazaka equipment. Results: Skin hydration and transepidermal water loss (TEWL) of thighs and buttocks differed significantly at all time points. Post hoc tests showed that each treatment caused a decrease in TEWL but no long-term effect was observed. For skin $\mathrm{pH}$, a significant difference was observed between the measurements I and IV. The lying position caused a greater reduction in the value of the acid-base balance. Conclusions: A series of vibration treatments improved the hydration and $\mathrm{pH}$ of the skin. The treatments limited TEWL; however, no long-term effect was observed.
\end{abstract}

Keywords: cellulite; corneometry; skin hydration; skin pH; TEWL; vibrotherapy; physical therapy; vibration stimulus

\section{Introduction}

Cellulite, defined as the atypical distribution of adipose tissue resulting from the growth and metabolic disorders of adipocytes and connective tissue, was once considered a normal state, and even a symbol of health, well-being, and sexual attractiveness [1]. This term was first used in the dermatological literature in the 1920s. There are also many synonymous terms used in the literature, such as gynoid lipodystrophy, panniculopathy, status protrusus cutis, dermopanniculosis deformans, adiposis edematosa, nodular liposclerosis, and edematofibrosclerotic panniculopathy $[2,3]$. Today, this esthetic defect is still a problem for most women. It affects approximately $85 \%$ of women over 20 years old and approximately $2 \%$ of men. Factors influencing the frequency of cellulite occurrence are disturbances in androgen secretion and hormone therapy [2]. Women suffering from cellulite experience a significant reduction in their quality of life [3]. Although cellulite is not considered a disease, it is one of the most poorly tolerated esthetic defects. Women with this disorder tend to have low self-esteem and levels of well-being. The emotional background accompanying the presence of this defect is most often shame, sadness, fear, and often a sense of hopelessness or helplessness. The results of Migasiewicz et al. [3] show that the type of experience and the subjective perception of cellulite change over time and are strongly correlated with the stage of cellulite advancement. While, in the first stage, this influence is relatively small, in the second stage, the psychological discomfort accompanying the disease can be considered significant, and in the third stage, it can be considered quite serious. 
The pathophysiology of cellulite is still not fully understood. However, several physiological and biochemical differences in subcutaneous adipose tissue in areas prone to cellulite development are indicated [4]. The initiating roles of estrogens and microcirculation disorders including reduced blood flow in the capillaries (even 35\% lower than in cellulite-free areas) are emphasized. However, it is also shown that disturbances in the lipolysis process, which is regulated by the nervous system, may play an important role in the pathomechanism of cellulite. There is also the theory of adipocyte receptors [1,5]. In a woman's body, adipose tissue is stored in specific body regions, such as the abdomen, hips, buttocks, and thighs. However, these areas differ in their sensitivity to hormones and trophic factors. As a consequence, they show different metabolic activity. For example, lipolytic reactivity (stimulated by catecholamines) is higher in visceral adipose tissue than in abdominal tissue and is lowest in adipose tissue in the thighs and buttocks. The role of genetic factors in cellulite development was also indicated [5]. Based on the above-cited observations, it could be concluded that, in the absence of clear causes, it is considered that cellulite changes have a multifactorial etiology.

The subjective symptoms of cellulite include the impression of heavy legs, swelling, paresthesia, tingling sensation, cramps, and periodic sudden mild pain. The objective ones include the appearance of "orange peel" in the affected areas, a "mattress symptom" characterized by unevenness and folding of the skin surface, its excessive pigmentation, and stretch marks. With the increase in the advancement of cellulite lesions, the skin tone changes from bluish or pale to yellow-gray in the most severe stage. Physical examination also shows swelling of the subcutaneous tissue, micro-extravasations, or trophic changes in the skin $[6,7]$.

A number of treatment methods for eliminating cellulite have been introduced, but their effectiveness (especially that of non-invasive methods) is still insufficient [8]. Vibrotherapy is a promising method to help fight cellulite that has not been studied exhaustively yet [9-13].

Vibration is a mechanical stimulus characterized by an oscillating movement. It is widely used in physiotherapy, especially in the treatment of pain [14-16]. It improves blood and lymph flow and helps to increase the elasticity of blood vessels [17]. It has been suggested that vibration exercise can increase the metabolic rate, which, in turn improves lean body mass without significantly affecting skinfold thickness [18]. Vibration treatments can affect glycemic control [19] and the composition of blood lipoproteins [20]. Used alone or in combination with other treatments, it can be a valuable tool in reducing the symptoms of cellulite [9-13]. However, it has not yet been investigated how the vibration itself affects the condition of the skin of the thighs and buttocks, assessed objectively thanks to the measurements of its selected features.

\section{Materials and Methods}

\subsection{Study Design}

The basic design of the present research was an experimental, randomized, observational study. The participants were preliminarily examined for the presence of contraindications for vibrotherapy $[11,15,16]$. During the recruitment process, the women were asked to complete a short personal questionnaire, and then the body composition, selected body circumferences, and the thickness of the skinfolds were measured. Then, the participants were randomly assigned to four groups: those receiving vibration treatments in a sitting position for $30 \mathrm{~min}(\mathrm{~S} 30)$ or $60 \mathrm{~min}$ (S60) and those receiving vibration treatments in a lying position with a $30 \mathrm{~min}$ (L30) or $60 \mathrm{~min}$ (L60) procedure.

Recruited women participated in a series of vibrotherapy treatments lasting 3 weeks (15 treatments in total). Treatments were performed once a day, excluding weekends. The first and last treatment of the series were performed on an empty stomach. Before the first treatment, the grade of cellulite was assessed. A single vibration treatment lasted 30 or $60 \mathrm{~min}$ and was performed in a lying or sitting position. Measurements of selected skin 
features were performed 4 times: before (I) and after the first treatment (II) and before (III) and after (IV) the last treatment in the series.

\subsubsection{Data Collection}

The JAWON MEDICAL (Korea) analyzer was used to estimate body composition using the bioelectric impedance method according to guidelines published by Dehghan and Merchant [21]. The grade of cellulite changes was assessed by the visual palpation method according to the Nürnberger and Müller scale [22]. It was determined according to the following scheme: grade 0 - healthy skin, no visible lesions even when the skin was pressed; grade 1-smooth skin, both in the standing and lying position, unevenness is visible only after applying pressure to the skin; grade 2-skin irregularities visible only when standing, smooth skin when lying down; grade 3-uneven skin visible both when standing and lying down. The evaluation was always performed by the same researcher. A clipper (Saehen) was used to measure the thickness of the selected skinfolds. Each measurement was performed in triplicate and the result was read after approximately $2 \mathrm{~s}$, in accordance with CDC guidelines [23].

Measurements of selected skin features were made after acclimatization to the conditions in the room before and up to $5 \mathrm{~min}$ after the vibrotherapy. The examined women were subjected to measurement of selected skin features in accordance with the protocol of the Skin Physiology Laboratory (CLNB, University of Physical Education in Krakow, Poland; PN-EN ISO 9001: 2015: PW-08606-19). A Multi Probe Adapter MPA base (Courage-Khazaka $\mathrm{GmBH}$, Cologne, Germany) and measuring probes from the same manufacturer were used: CM 825 corneometer (measurement error: $\pm 3 \%$ ); TM 300 tewameter (measurement error: $\pm 0.5 \mathrm{~g} / \mathrm{h} / \mathrm{m}^{2}$ for relative humidity $\geq 30 \%$ and $\pm 1.0 \mathrm{~g} / \mathrm{hm} 2$ for $\mathrm{RH} \leq 30 \%$ ); Skin $\mathrm{pH}$-meter PH 905 (error: \pm 0.1 ). The conditions (ambient temperature and air humidity) were within the range specified by the manufacturer of the measuring instruments. Measurements were taken on the thigh and buttock, each time taking three readings on the non-overlapping areas, and a single result was given as the mean of the three readings.

\subsubsection{Participants}

Sixty healthy, young women, with no contraindications to vibration treatments [11], with symptoms of cellulite (of at least grade I on the Nurnberg-Muller scale [22]), were recruited to participate in the study. After becoming acquainted with the purpose of the project and the planned measurement methods, the respondents gave their consent in writing to participate. The full protocol was completed by 57 women. The resignations resulted from the appearance of headaches (1 participant) and seasonal infections (2 participants). Basic characteristics of the participants are given in Table 1.

\subsubsection{Source of Vibrational Stimuli}

The vibration stimulus was generated by the MMT device (Vitberg, Poland). The oscillatory-cycloidal vibrations used in this research study were generated by a motor operating in the range of $18-39 \mathrm{~Hz}$. The symmetrical work of the side modules in the cushions placed on the sides of the body was assumed. Characteristics of the device and description of treatment positions are provided in the work of Piotrowska and CzerwińskaLedwig [11]. 
Table 1. Characteristics of the project participants.

\begin{tabular}{|c|c|c|c|c|c|c|}
\hline & \multirow[t]{2}{*}{ Total } & \multicolumn{2}{|c|}{ Sitting } & \multicolumn{2}{|c|}{ Lying } & \multirow{3}{*}{$p$} \\
\hline & & $30^{\prime}$ & $60^{\prime}$ & $30^{\prime}$ & $60^{\prime}$ & \\
\hline (n) & 57 & 15 & 15 & 13 & 14 & \\
\hline Age (years) & $22.84 \pm 5.34$ & $22.47 \pm 4.76$ & $21.67 \pm 3.39$ & $23.92 \pm 7.18$ & $23.50 \pm 5.91$ & 0.2512 \\
\hline Hight $(\mathrm{cm})$ & $166.42 \pm 5.62$ & $164.86 \pm 4.07$ & $156.87 \pm 5.16$ & $165.69 \pm 5.99$ & $169.36 \pm 5.58$ & 0.1364 \\
\hline Body mas (kg) & $62.28 \pm 8.43$ & $60.05 \pm 6.96$ & $60,73 \pm 8.18$ & $63.58 \pm 9.67$ & $65.1 \pm 8.76$ & 0.0748 \\
\hline BMI & $22.45 \pm 2.55$ & $22.06 \pm 2.17$ & $22.00 \pm 1.88$ & $23.16 \pm 3.34$ & $22.69 \pm 2.81$ & 0.1942 \\
\hline Fat $(\%)$ & $23.75 \pm 4.08$ & $24.92 \pm 3.58$ & $23.59 \pm 4.16$ & $24.63 \pm 4.44$ & $21.84 \pm 3.83$ & 0.3248 \\
\hline Water $(\%)$ & $56.08 \pm 3.23$ & $56.14 \pm 3.00$ & $56.13 \pm 2.92$ & $55.3 \pm 3.67$ & $56.68 \pm 3.56$ & 0.8885 \\
\hline Arm circumference $(\mathrm{cm})$ & $27.71 \pm 2.88$ & $27.62 \pm 3.03$ & $28.01 \pm 2.25$ & $27.87 \pm 2.85$ & $27.34 \pm 3.54$ & 0.7789 \\
\hline Waist circumference $(\mathrm{cm})$ & $72.55 \pm 6.39$ & $71.16 \pm 6.03$ & $72.17 \pm 5.40$ & $74.55 \pm 7.47$ & $72.61 \pm 6.87$ & 0.2706 \\
\hline Hip circumference $(\mathrm{cm})$ & $97.61 \pm 6.68$ & $96.03 \pm 7.19$ & $97.83 \pm 6.83$ & $98.41 \pm 6.82$ & $98.31 \pm 6.29$ & 0.4239 \\
\hline Thigh circumference $(\mathrm{cm})$ & $56.98 \pm 4.27$ & $56.13 \pm 4.60$ & $57.05 \pm 3.99$ & $57.24 \pm 4.29$ & $57.56 \pm 4.51$ & 0.4769 \\
\hline Calf circumference $(\mathrm{cm})$ & $36.39 \pm 2.54$ & $36.00 \pm 2.63$ & $36.25 \pm 2.53$ & $36.48 \pm 1.88$ & $36.89 \pm 3.11$ & 0.4088 \\
\hline Triceps skinfold (mm) & $26.05 \pm 6.73$ & $27.00 \pm 4.36$ & $27.73 \pm 6.17$ & $27.12 \pm 7.01$ & $22.25 \pm 8.2$ & 0.1213 \\
\hline Subscapular skinfold (mm) & $20.84 \pm 7.00$ & $21.03 \pm 7.51$ & $20.53 \pm 5.71$ & $22.46 \pm 8.22$ & $19.46 \pm 6.84$ & 0.9474 \\
\hline Abdominal skinfold (mm) & $28.59 \pm 8.60$ & $29.87 \pm 7.51$ & $27.60 \pm 9.70$ & $31.38 \pm 8.89$ & $25.68 \pm 8.00$ & 0.8943 \\
\hline Hip skinfold (mm) & $21.23 \pm 7.85$ & $21.90 \pm 8.36$ & $22.27 \pm 7.47$ & $22.54 \pm 8.61$ & $18.17 \pm 6.96$ & 0.3906 \\
\hline Thigh skinfold (mm) & $40.29 \pm 8.88$ & $40.73 \pm 7.43$ & $42.13 \pm 8.14$ & $40.58 \pm 10.70$ & $37.57 \pm 9.54$ & 0.3096 \\
\hline
\end{tabular}

\subsection{Statistical Analysis}

The results are presented as means $( \pm S D)$. After assessing the type of distribution (Shapiro-Wilk test), the effects of the treatments were assessed by one-way analysis of variance (ANOVA) after sphericity correction (Huynh-Feldt). Bonferroni post hoc test was used. The level of significance was $p<0.05$. Effect size was assessed with use of the $\eta^{2}$ parameter. All analyses were performed using the STATISTICA 13 software (StatSoft, Tulsa, OK, USA).

\subsection{Ethics}

The project received a positive opinion from the Bioethical Committee of PMWSZ in Opole No. KB/56/N02/2019 and did not violate the principles of the Helsinki Declaration. The applied intervention in the form of vibrotherapy met the guidelines for research using whole-body vibration as a treatment regimen in humans $[15,16]$

\section{Results}

\subsection{Skin Hydration}

The results of the skin hydration measurements on the thighs obtained at four time points, i.e., before (I) and after (II) the first treatment, and before (III) and after (IV) the last treatment, were significantly different $\left(\mathrm{F}(2.269)=18.697 p<0.01 ; \eta^{2}=0.072\right)$. No significance was found for single treatment duration and treatment position. There were no interactions between these variables. However, it can be seen in the graphs that the $60 \mathrm{~min}$ treatments allowed for higher (but non-significant) corneometer readings (Figure 1a). The post hoc test showed that the results obtained before and after the first treatment were significantly different $\left(p=0.003 ; \eta^{2}=-0.474\right)$. A significant difference between measurement points I and III was also indicated $\left(p<0.001 ; \eta^{2}=-0.714\right)$. No difference between III and IV (adaptation effect) could be identified. In the between-subjects effects analysis for the four experimental groups, there were no significant differences in the level of skin hydration on the thigh.

The results of skin hydration measurements on the buttock showed great similarity to the changes seen on the thigh. Significant differences in the results obtained during the project were indicated $\left(\mathrm{F}(2.602)=11.124 p<0.001 ; \eta^{2}=0.043\right)$. The significance of the duration of a single treatment was not indicated (although, again, the graphs show higher values for the 60 min treatments - see Figure 2a,b-treatment position, and the presence of interactions between these variables). The post hoc test showed the difference between measurement I and III (influence of a series of treatments). Contrary to the case of the thigh, there was no indication of the influence of a single treatment on the observed effect. For the buttock skin hydration, no between-subjects effects differences were found. 

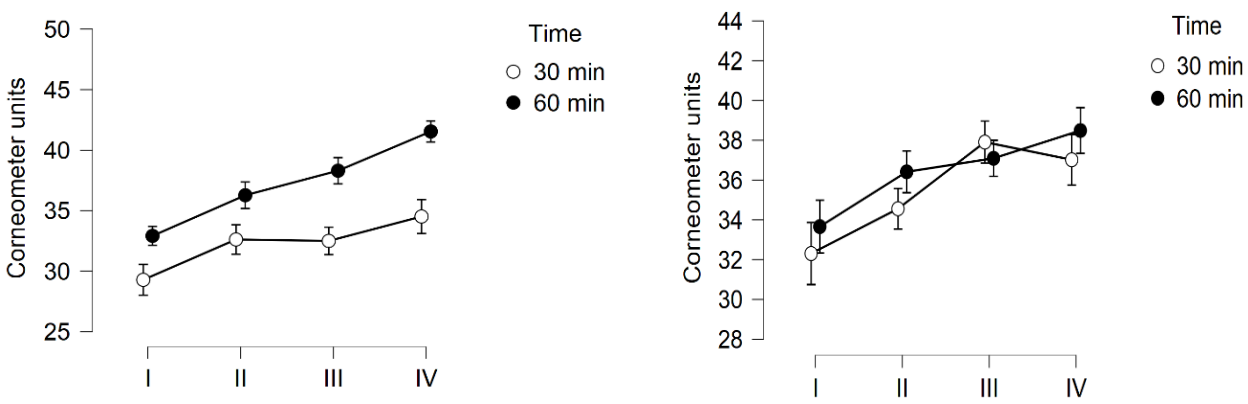

(a)

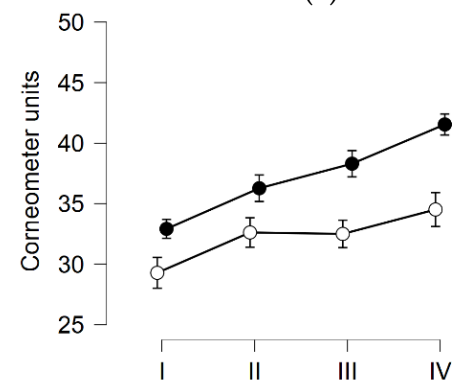

(b)
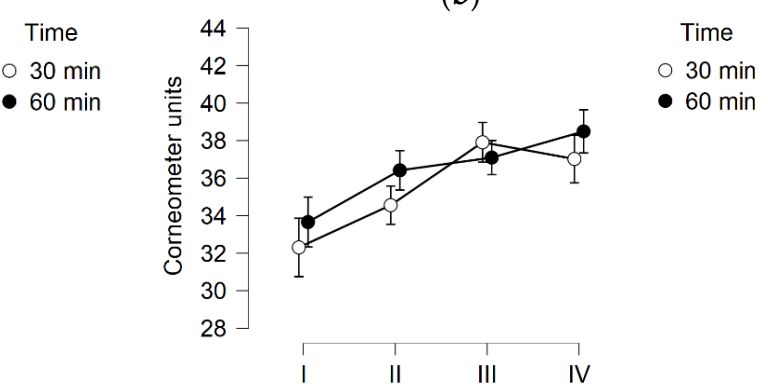

(d)

Figure 1. Results of corneometer measurements of thigh's skin hydration after 3 weeks of local vibration therapy. (a) -Vibrotherapy in lying position; (b)-Vibrotherapy in sitting position; (c)-Vibrotherapy for $30 \mathrm{~min}$; (d) - Vibrotherapy for $60 \mathrm{~min}$. I-Baseline; II-After first treatment; III-Before last treatment; IV-After last treatment.

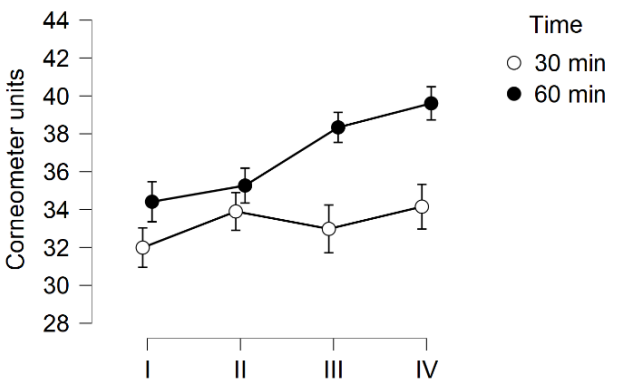

(a)

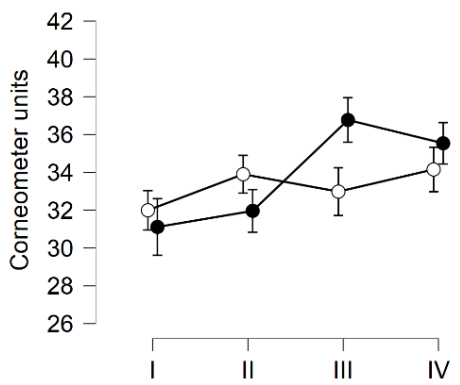

(c)

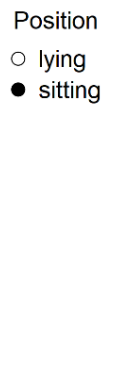

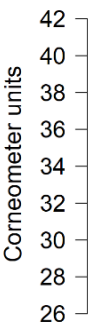

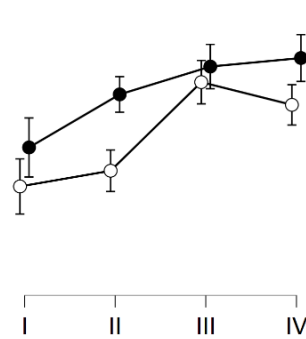

(b)
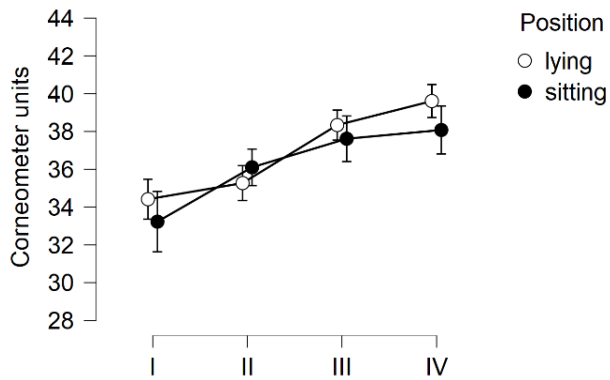

(d)

Figure 2. Results of corneometer measurements of buttock's skin hydration after 3 weeks of local vibration therapy. (a)-Vibrotherapy in lying position; (b)-Vibrotherapy in sitting position; (c) - Vibrotherapy for $30 \mathrm{~min}$; (d)—Vibrotherapy for $60 \mathrm{~min}$. I-Baseline; II-After first treatment; III-Before last treatment; IV-After last treatment.

\subsection{TEWL}

The results of the TEWL measurement of the skin of the thighs obtained at the four time points were significantly different $\left(F(2.312)=12.024 p<0.001 ; \eta^{2}=0.112\right)$. The significance 
of time, position, or interactions between these variables was not indicated. The post hoc test showed significant differences for measurements I and II $\left(p<0.001 ; \eta^{2}=0.603\right)$ and for III and IV $\left(p<0.001 ; \eta^{2}=0.510\right)$. There were no differences between the first and third measurements. The between-subjects effects analysis for the four experimental groups showed no significant differences. The results obtained in participants who underwent procedures for 30 and 60 min were statistically significant $\left(p=0.019 ; \eta^{2} 0.096\right)$, and the higher values of TEWL were observed in women who underwent $30 \mathrm{~min}$ procedures (Figure 3c).

The buttock skin TEWL results obtained at the four time points differed significantly $\left(\mathrm{F}(2.630)=10.569 ; p<0.001 ; \eta^{2}=0.102\right)$ and are shown in Figure 4. However, the significance of time, position, or interactions between these variables was not indicated. Similarly to the skin on the thighs, the post hoc test showed that there were significant differences for measurements I and II ( $\left.p<0.001 ; \eta^{2}=0.582\right)$ and for measurements III and IV $(p<0.004$; $\left.\eta^{2}=0.460\right)$. There were no differences between the first and third measurements. The between-subjects effects analysis for the four experimental groups showed no significant differences.

\subsection{Skin $p H$}

The results of the thigh skin $\mathrm{pH}$ measurement obtained at the four time points differed significantly $\left(\mathrm{F}(2.725)=3.411 p=0.023 ; \eta^{2}=0.029\right)$. The modulating role of the treatment position was indicated $\left(\mathrm{F}(2.725)-4.706 p=0.005 ; \eta^{2}=-0.039\right)$, with an indication of the lying position ( $p=0.026 ; \eta^{2}=-0.304$ ) (Figure $5 \mathrm{a}$ ). The duration of the procedure did not cause significant changes. The presence of interactions (time $x$ treatment position) was also not indicated. The post hoc test showed that the effect of the first treatment was small $\left(p=0.104 ; \eta^{2}=0.318\right)$, and significant differences were indicated between the first and fourth measurement $\left(p=0.032 ; \eta^{2}=0.374\right)$. The between-subjects effects analysis again showed the significance of the treatment position ( $\left.\mathrm{F}(1)-5.274 p=0.026 ; \eta^{2}=0.041\right)$, and in the post hoc tests, it was shown that these differences concerned the last treatment in the series.

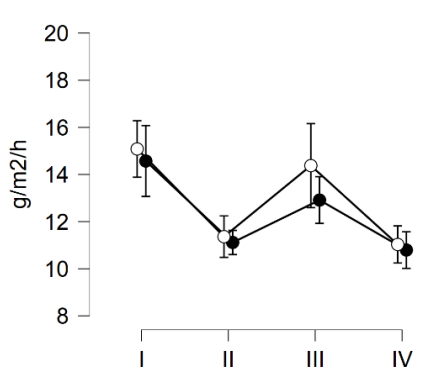

(a)

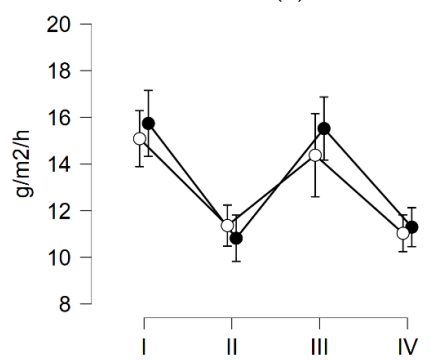

(c)
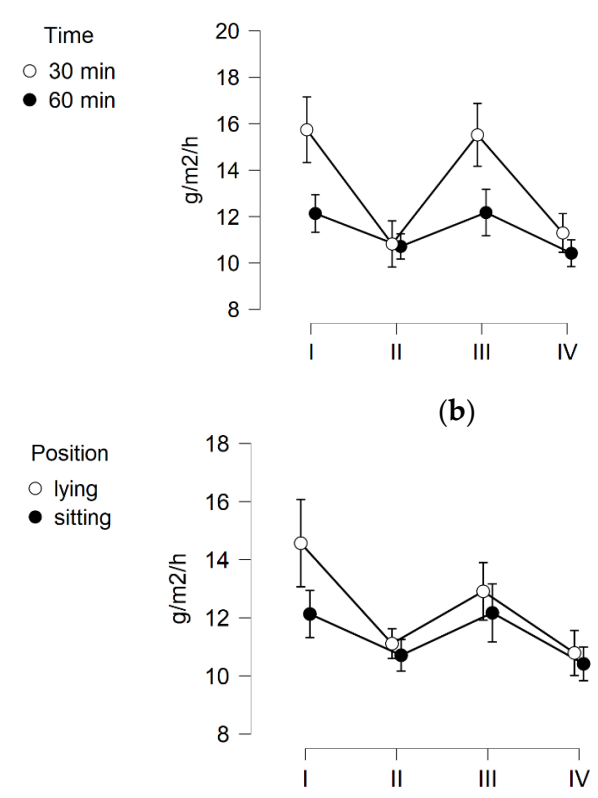

(d)

Figure 3. The results of tewameter measurements of thigh's skin hydration after 3 weeks of local vibration therapy. (a)-Vibrotherapy in lying position; (b)-Vibrotherapy in sitting position; (c)-Vibrotherapy for $30 \mathrm{~min}$; (d) —Vibrotherapy for $60 \mathrm{~min}$. I-Baseline; II-After first treatment; III-Before last treatment; IV—After last treatment. 


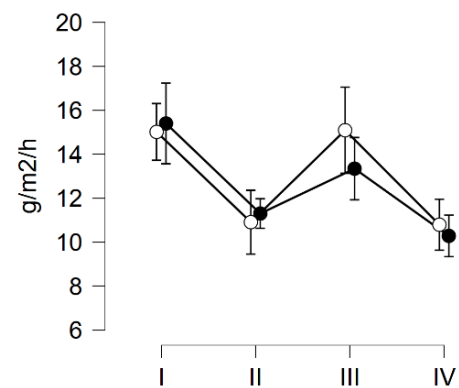

(a)

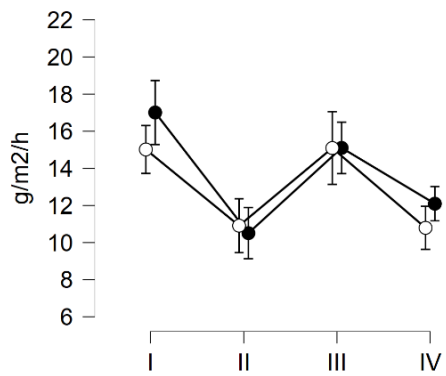

(c)
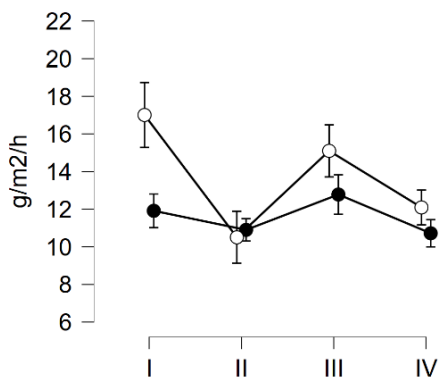

(b)
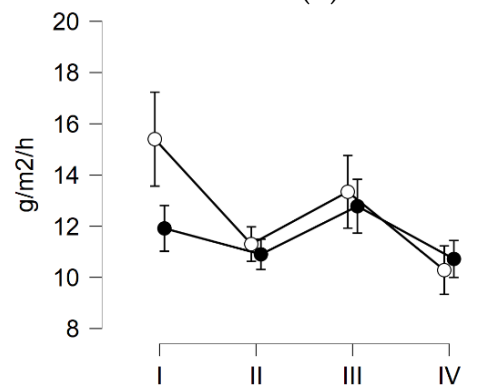

(d)

Figure 4. The results of tewameter measurements of buttock's skin hydration after 3 weeks of local vibration therapy. (a) - Vibrotherapy in lying position; (b)-Vibrotherapy in sitting position; (c) - Vibrotherapy for $30 \mathrm{~min}$; (d) - Vibrotherapy for $60 \mathrm{~min}$. I-Baseline; II-After first treatment; III-Before last treatment; IV-After last treatment.

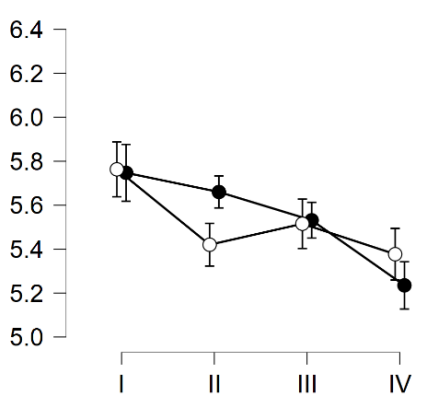

(a)

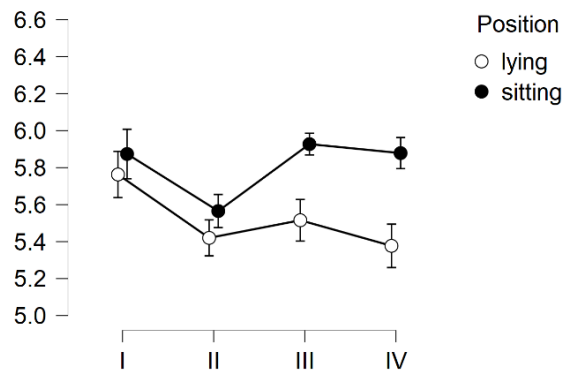

(c)
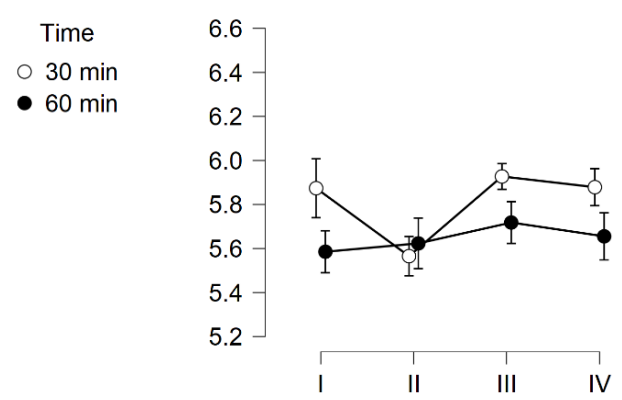

(b)
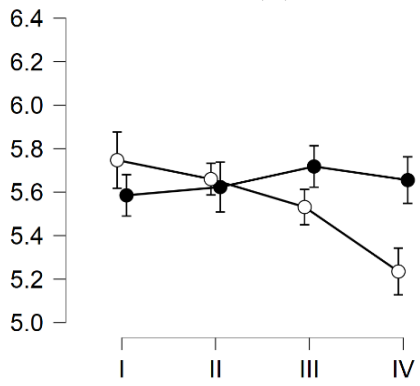

(d)

Figure 5. The results of $\mathrm{pH}$ measurements of thigh's skin hydration after 3 weeks of local vibration therapy. (a) - Vibrotherapy in lying position; (b) - Vibrotherapy in sitting position; (c) —Vibrotherapy for $30 \mathrm{~min}$; (d)-Vibrotherapy for $60 \mathrm{~min}$. I-Baseline; II-After first treatment; III-Before last treatment; IV-After last treatment.

The results of the buttock skin $\mathrm{pH}$ measurement again were consistent with the results obtained for the thighs presented above, and they differed significantly $(\mathrm{F}(2.630)=4.940$ $\left.p=0.023 ; \eta^{2}=0.046\right)$. Similarly, the modulating role of the treatment position was indicated 
$\left(\mathrm{F}(2.630)=3.326 p=0.027 ; \eta^{2}-0.031\right)$, with an indication of the lying position $(p=0.026 ;$ $\left.\eta^{2}=-0.304\right)$ (Figure 6a). The post hoc test showed the effect of the first treatment $(p=0.014$; $\left.\eta^{2}=0.410\right)$. The last treatment did not cause any significant changes. The between-subjects effects analysis showed no differences.

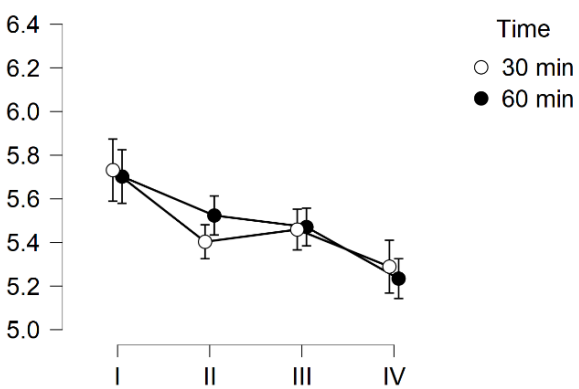

(a)

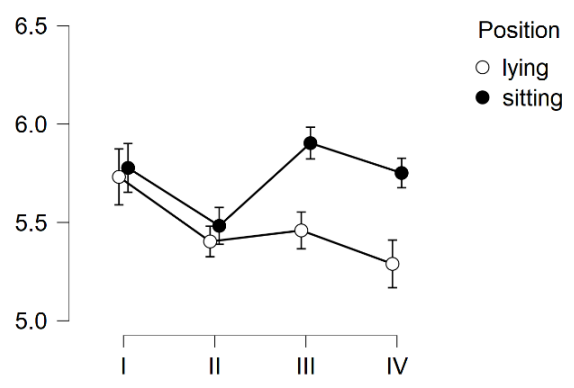

(c)

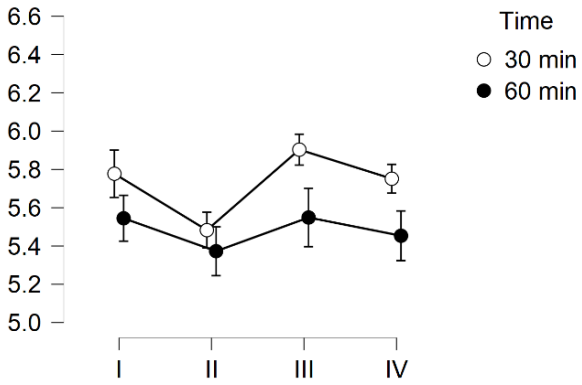

(b)

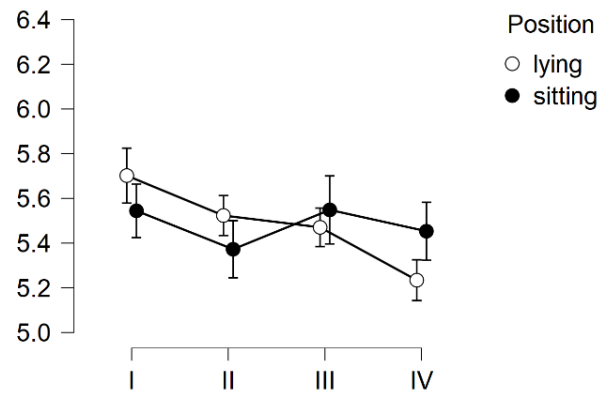

(d)

Figure 6. The results of $\mathrm{pH}$ measurements of buttock's skin hydration after 3 weeks of local vibration therapy. (a)—Vibrotherapy in lying position; (b) - Vibrotherapy in sitting position; (c)-Vibrotherapy for $30 \mathrm{~min}$; (d)_Vibrotherapy for $60 \mathrm{~min}$. I-Baseline; II-After first treatment; III-Before last treatment; IV-After last treatment.

\section{Discussion}

The results presented in this paper show that vibrotherapy, used as a method of eliminating cellulite, has an impact on the basic characteristics of the skin. It was indicated that a single treatment improves the hydration of the skin of the thighs. More importantly, the series of treatments increased the skin hydration of both examined regions (the thighs and buttocks). We also observed that both the first and the last treatment resulted in a significant decrease in TEWL. There was no change in the TEWL in the third measurement compared to the first one, which would indicate a change in the skin's barrier function. The observed changes in the acid-base balance reaction of the skin were inconclusive. The change was time-dependent and relied on the treatment position. The time of a single procedure was not important, and no long-term effect on this feature of the skin was indicated (measurement III did not differ significantly from I). The significant difference found (between the first and last measurement) shows the complex type of response to the series of treatments used.

The importance of this study is primarily an indication that anti-cellulite vibration treatments, in addition to being effective-which was also confirmed before [9-13] - are safe for the skin as the basic barrier organ that guarantees the integrity of the human body. The obtained results show that they have a beneficial effect by improving skin hydration, and each treatment reduces TEWL.

In subjects with cellulite, the skin may be heavily burdened due to the multifactorial pathomechanism of cellulite changes. Impaired microcirculation comes to the fore here. It reduces the oxygenation of the endothelium. The consequences of local hypoxia are swelling, formation of micro-aneurysms, and micro-extravasations. Further changes include an increase in the hydrostatic pressure of the intercellular fluid and an increase in the 
protein content in the tissue fluid. In such conditions, adipocytes entangled with collagen fibers are exposed to oxygen deficiency and increased oxidative stress. Such conditions cause their deformation and degeneration, which in turn leads to the formation of nodules in the tissue, visible on the skin as its unevenness [1,5]. Vibration may have a beneficial effect in the course of these changes in many directions: it can improve the activity of skin cells in the synthesis of structural proteins, which enhances the flexibility and elasticity of tissues. It is also of significant importance in ameliorating circulation [24-26] and tissue drainage [27]. Improvements in these areas may result in a change in basic skin parameters.

In vitro studies indicate that the vibration stimulus may be the factor generating a biological response, and this relationship concerns fibroblasts in particular [28-30]. The effect on the tissue subjected to the vibration stimulus in the in vivo model is still poorly described. It can be expected that this effect may mimic the massage effect. In the study by Caberlotto et al. [31], it has been shown that vibration (in particular, at 60 and $90 \mathrm{~Hz}$ ) induces favorable structural changes in the dermis, associated with the synthesis of fibronectin, procollagen 1, and tropoelastin [31].

Vibration, as a mechanical stimulus, also increases circulation in the skin [24-26,32,33]. The frequency and levels of vibration acceleration used in the cited works, as well as in our project, were within the safe range [34]. Importantly, the effect of this type of stimulus does not end with the end of its action. The study by Okuwa et al. indicated that vibrations improve microcirculation for at least $60 \mathrm{~min}$ after the action of a mechanical stimulus [35]. The mechanism underlying these observations was verified in the study by Ichiok et al. [36]. The authors used NG-nitro-L-arginine methyl ester (L-NAME), a nonselective nitric oxide (NO) synthase inhibitor that blocks NO production. Using a mouse model of microcirculation, the authors confirmed that the vibrations significantly increased blood flow 5 and $15 \mathrm{~min}$ after the stimulus was applied, and this effect was dependent on the possibility of NO synthesis. Johnson et al. have confirmed this mechanism in humans [33].

The effect of vibration on the activity of living skin cells and for the synthesis of tissue matrix proteins may explain the effect of a series of treatments on the level of skin hydration. The newly produced proteins have a higher degree of hydration and will thus influence the corneometric readings. A single treatment improves skin hydration rather due to its stimulating effect on the cutaneous microcirculation or the direct effect of friction on the relocation of water to the outer areas of the skin. Of course, the impact of the first treatment can also be explained by the action of stress hormones and sympathetic stimulation of the activity of the sweat glands [37]. However, the long-term effect (I vs. III) casts doubts about such a mechanism of the observed changes in the level of skin hydration.

One of the most important parameters characterizing the skin barrier is TEWL [38-40]. According to the definition, it is the amount of water that diffuses from the inside of the skin, through the stratum corneum. Increased TEWL is usually associated with impaired skin barrier function. Low TEWL is considered an indicator of normal epidermal barrier integrity. This parameter is the most widely used objective measurement for assessing the barrier function of healthy skin but also in patients with dermatologic diseases associated with skin barrier imperfection, e.g., atopic dermatitis [41].

Our results showed that both the first and the last treatment significantly reduced TEWL in both examined skin areas (Figures 3 and 4). As mentioned before, the amount of water lost through the skin is a measure of its barrier function. Therefore, it can be indicated that each single treatment would improve the barrier function, which can be practically used, e.g., a cosmetic with active ingredients applied to the skin - after the action of vibration, it will be deposited in the skin for a longer time, and active, nourishing, and moisturizing ingredients will be able to modify the properties of individual skin layers. However, the series of treatments did not affect the TEWL, which means that, despite the beneficial effects of an individual treatment, the initial TEWL value does not change. The question remains as to whether the improvement in TEWL will be permanent when the series of treatments is extended by further weeks. 
Another important biophysical parameter of the skin is its $\mathrm{pH}$. The mean physiological $\mathrm{pH}$ value of the surface of human skin is about 4.8 [42]. The results obtained in our participants were much higher, and, for all groups, the values oscillated around 5.8. Skin $\mathrm{pH}$ is influenced by the ingredients forming the lipid coat and the ingredients of the natural moisturizing factor (NMF), such as free amino acids, sodium pyrrolidone carboxylic acid, lactates, urea, mineral salts, ammonia, sugars, and uric acid. The physiological, acidic $\mathrm{pH}$ has a protective function $[42,43]$. The $\mathrm{pH}$ measurement is assessed by the presence of water deposited on the surface of the skin [42], and in our study, the TEWL parameter decreased, so every vibrational session led to a change in the amount of water on the surface of the skin. Therefore, the acid-base balance must have changed. The sum of minor, insignificant changes led to the significant difference observed between measurements I and IV.

As mentioned at the beginning of this section, the initial $\mathrm{pH}$ values of the skin of the thighs and buttocks in the studied women were relatively high. It is difficult to find comparative sources in the available literature, and the $\mathrm{pH}$ of the skin of these areas is not a common topic of scientific research. It should be emphasized that none of the proposed treatment positions or any time protocol of the vibration treatment caused an increase in $\mathrm{pH}$, and, although often in a statistically insignificant way, both the first and the last treatment caused drops in the $\mathrm{pH}$ meter readings. This may be due to the formation of sweat with NMF components, which, on the one hand, will explain the improvement in hydration; on the other hand, the acidic components of NMF may explain the presence of acid-base changes.

According to our knowledge, this is the first work showing the effect of vibrotherapy on the condition of the skin. It is widely recognized that the effects of vibration on the skin can be compared to the effects of a massage. The similarities are related to the influence on the blood flow in the vascular bed of the skin. Moreover, as with vibrotherapy, the effect of a one-time treatment and the long-term effect may be different [44].

During body massage treatments, various types of lubricants are used. Lubricant oils are a factor that makes it impossible to compare the results directly with the results obtained in this study. They largely affect the condition of the epidermis barrier function, skin $\mathrm{pH}$, and its hydration [45].

\section{Conclusions}

As vibration treatments have previously been shown to reduce the symptoms of cellulite, this study also demonstrated that vibrotherapy improves the skin hydration on the thighs and buttocks. The treatments limit transepidermal water loss; however, no long-term effect on the TEWL value of the skin of the thighs and buttocks after 3 weeks was observed. The effect of a series of treatments on the acid-base balance of the skin depends on the treatment position, and the lying position yields a greater reduction in the value of the acid-base reaction. The question remains as to whether the extended protocol will further improve the skin's hydration status and allow a lasting improvement in skin TEWL and $\mathrm{pH}$ to be observed.

Author Contributions: Conceptualization and methodology: A.P. All other tasks were performed by A.P. and O.C.-L. All authors have read and agreed to the published version of the manuscript.

Funding: This research was funded by Narodowe Centrum Badań i Rozwoju, Poland Grant/Award Number: POIR.01.01.01-00-1208/17. The paper was exempt from the APC fee.

Institutional Review Board Statement: The study was conducted in accordance with the Declaration of Helsinki and approved by the Bioethical Committee of PMWSZ in Opole for studies involving humans (No. KB/56/N02/2019).

Informed Consent Statement: Written, informed consent was obtained from all subjects involved in the study.

Data Availability Statement: Data available on request from the corresponding author. 
Acknowledgments: The authors would like to thank all the cosmetology students of the University of Physical Education in Krakow who helped with this project. We also thank Jacek Sikora for his substantive technical assistance in working with the devices generating the vibration stimulus.

Conflicts of Interest: The authors declare no conflict of interest. The grant funders had no role in the design of the study; in the collection, analyses, or interpretation of data; in the writing of the manuscript, or in the decision to publish the results.

\section{References}

1. Bass, L.S.; Kaminer, M.S. Insights Into the Pathophysiology of Cellulite: A Review. Dermatol. Surg. 2020, 46, S77-S85. [CrossRef] [PubMed]

2. Friedmann, D.P.; Vick, G.L.; Mishra, V. Cellulite: A review with a focus on subcision. Clin. Cosmet. Investig. Dermatol. 2017, 10, 17-23. [CrossRef] [PubMed]

3. Khan, M.H.; Victor, F.; Rao, B.; Sadick, N.S. Treatment of cellulite. Part I. Pathophysiology. J. Am. Acad. Dermatol. 2010, 62, 361-370. [CrossRef]

4. Migasiewicz, A.; Podbielska, H.; Bauer, J. Women's quality of life depending on the cellulite stage. Acta Bio-Opt. Et Inform. 2014, 20, 217-226.

5. Emanuele, E.; Bertona, M.; Geroldi, D. A multilocus candidate approach identifies ACE and HIF1A as susceptibility genes for cellulite. J. Eur. Acad. Dermatol. Venereol. 2010, 24, 930-935. [CrossRef] [PubMed]

6. Gałązka, M.; Galęba, A.; Nurein, H. Cellulite as a medical and aesthetic problem—etiopathogenesis, symptoms, diagnosis and treatment. Hygeia Public Health 2014, 49, 425-430.

7. Sadick, N. Treatment for cellulite. Int. J. Women's Dermatol. 2019, 5, 68-72. [CrossRef]

8. Alizadeh, Z.; Halabchi, F.; Mazaheri, R.; Abolhasani, M.; Tabesh, M. Review of the mechanisms and effects of noninvasive body contouring devices on cellulite and subcutaneous fat. Int. J. Endocrinol. Metab. 2016, 14, e36727. [CrossRef]

9. Pilch, W.; Nastałek, M.; Piotrowska, A.; Czerwińska-Ledwig, O.; Zuziak, R.; Maciorowska, A.; Golec, J. The effects of a 4-week vibrotherapy programme on the reduction of adipose tissue in young women with cellulite-A pilot study. Rehabil. Med. 2018, 22, 18-24. [CrossRef]

10. Pilch, W.; Czerwińska-Ledwig, O.; Chitryniewicz-Rostek, J.; Nastałek, M.; Krȩzałek, P.; Jȩdrychowska, D.; Totko-Borkusewicz, N.; Uher, I.; Kaško, D.; Tota, L.; et al. The Impact of Vibration Therapy Interventions on Skin Condition and Skin Temperature Changes in Young Women with Lipodystrophy: A Pilot Study. Evid.-Based Complement. Altern. Med. 2019, 2019, 1-9. [CrossRef]

11. Piotrowska, A.; Czerwińska-Ledwig, O. Effect of local vibrotherapy in sitting or lying position in two time protocols on the cellulite grade and change of body circumferences in women with cellulite. J. Cosmet. Dermatol. 2021, 00, 1-10. [CrossRef] [PubMed]

12. Savoia, A.; Landi, S.; Vannini, F.; Baldi, A. Low-level laser therapy and vibration therapy for the treatment of localized adiposity and fibrous cellulite. Dermatol. Ther. 2013, 3, 41-52. [CrossRef] [PubMed]

13. Cristovam, D.N.; Botelho, S.; Andrade, M.F.; Marques, J.; Sousa, L. Whole-body vibration in the reduction of the cellulite. J. Cosmet. Laser Ther. 2019, 21, 278-285. [CrossRef] [PubMed]

14. Rittweger, J.; Beller, G.; Armbrecht, G.; Mulder, E.; Buehring, B.; Gast, U.; Dimeo, F.; Schubert, H.; de Haan, A.; Stegeman, D.F.; et al. Prevention of bone loss during 56 days of strict bed rest by side-alternating resistive vibration exercise. Bone 2010, 46, 137-147. [CrossRef]

15. Wuestefeld, A.; Fuermaier, A.B.M.; Bernardo-Filho, M.; Da Cunha De Sá-Caputo, D.; Rittweger, J.; Schoenau, E.; Stark, C.; Marin, P.; Seixas, A.; Judex, S.; et al. Towards reporting guidelines of research using whole-body vibration as training or treatment regimen in human subjects-A Delphi consensus study. PLoS ONE 2020, 15, e0235905. [CrossRef] [PubMed]

16. Van Heuvelen, M.J.G.; Rittweger, J.; Judex, S.; Sañudo, B.; Fuermaier, A.B.M.; Tucha, O.; Nyakas, C.; Mar, P.J.; Taiar, R. Reporting Guidelines for Whole-Body Vibration Studies in Humans, Animals and Cell Cultures: A Consensus Statement from an International Group of Experts. Biology 2021, 10, 965. [CrossRef]

17. Otsuki, T.; Takanami, Y.; Aoi, W.; Kawai, Y.; Ichikawa, H.; Yoshikawa, T. Arterial stiffness acutely decreases after whole-body vibration in humans. Acta Physiol. 2008, 194, 189-194. [CrossRef]

18. Uher, I. Vibration Therapy and Its Influence on Health. Biomed. J. Sci. Tech. Res. 2018, 6, 1-4. [CrossRef]

19. Piotrowska, A.; Tota, Ł.; Czerwińska-Ledwig, O.; Bigosińska, M.; Potok, H.; Cisoń-Apanasewicz, U.; Zuziak, R.; Wrześniewski, K.; Tyka, A.; Żmuda-Pałka, M.; et al. Effect of Vibration Therapy on Fasting Glucose, Insulin Level and Homa2 Score in Women With Pre-Diabetes History. J. Kinesiol. Exerc. Sci. Antropomotoryka JKES 2018, 81, 11-19. [CrossRef]

20. Piotrowska, A.M.; Bigosińska, M.; Potok, H.; Cisoń-Apanasewicz, U.; Czerwińska-Ledwig, O.; Tota, Ł.M.; Zuziak, R.; Pałka, T.; Pilch, W. Impact of oscillatory-cycloid vibration interventions on body composition, waist and hip circumference, and blood lipid profile in women aged over 65 years with hypercholesterolaemia. Prz. Menopauzalny 2018, 17, 161-167. [CrossRef]

21. Dehghan, M.; Merchant, A.T. Is bioelectrical impedance accurate for use in large epidemiological studies? Nutr. J. 2008, 7, 1-7. [CrossRef] [PubMed]

22. Nürnberger, F.; Müller, G. So-Called Cellulite: An Invented Disease. J. Dermatol. Surg. Oncol. 1978, 4, 221-229. [CrossRef] [PubMed] 
23. National Health and Nutrition Examinatory Survey (NHANES). Anthropometry Procedures Manual. 2007. Available online: https://www.cdc.gov/nchs/data/nhanes/nhanes_07_08/manual_an.pdf (accessed on 3 December 2021).

24. Çakar, H.I.; Doğan, S.; Kara, S.; Rittweger, J.; Rawer, R.; Zange, J. Vibration-related extrusion of capillary blood from the calf musculature depends upon directions of vibration of the leg and of the gravity vector. Eur. J. Appl. Physiol. 2017, 117, 1107-1117. [CrossRef]

25. Ren, W.; Pu, F.; Luan, H.; Duan, Y.; Su, H.; Fan, Y. Effects of Local Vibration With Different Intermittent Durations on Skin Blood Flow Responses in Diabetic People. Front. Bioeng. Biotechnol. 2019, 7, 310. [CrossRef]

26. Nakagami, G.; Sanada, H.; Matsui, N.; Kitagawa, A.; Yokogawa, H.; Sekiya, N.; Ichioka, S.; Sugama, J.; Shibata, M. Effect of vibration on skin blood flow in an in vivo microcirculatory model. BioSci. Trends 2007, 1, 161-166. [PubMed]

27. Stewart, J.M.; Karman, C.; Montgomery, L.D.; McLeod, K.J. Plantar vibration improves leg fluid flow in perimenopausal women. Am. J. Physiol.-Regul. Integr. Comp. Physiol. 2005, 288, 623-629. [CrossRef]

28. Farran, A.J.E.; Teller, S.S.; Jia, F.; Clifton, R.J.; Duncan, R.L.; Jia, X. Design and characterization of a dynamic vibrational culture system. J. Tissue Eng. Regen. Med. 2013, 7, 213-225. [CrossRef]

29. Jungbauer, S.; Gao, H.; Spatz, J.P.; Kemkemer, R. Two characteristic regimes in frequency-dependent dynamic reorientation of fibroblasts on cyclically stretched substrates. Biophys. J. 2008, 95, 3470-3478. [CrossRef]

30. Kutty, J.K.; Webb, K. Vibration stimulates vocal mucosa-like matrix expression by hydrogel-encapsulated fibroblasts. J. Tissue Eng. Regen. Med. 2010, 4, 62-72. [CrossRef]

31. Caberlotto, E.; Bernal, M.; Miller, Z.; Poole, A.; Ruiz, L.; Tanter, M.; Gennisson, J.L.; Querleux, B. Controlled mechanical vibration and impacts on skin biology. Ski. Res. Technol. 2019, 25, 881-889. [CrossRef]

32. Tzen, Y.; Weinheimer-haus, E.M.; Corbiere, T.F.; Koh, T.J. Increased skin blood flow during low intensity vibration in human participants: Analysis of control mechanisms using short-time Fourier transform. PLoS ONE 2018, 13, e0200247. [CrossRef] [PubMed]

33. Johnson, P.K.; Feland, J.B.; Johnson, A.W.; Mack, G.W.; Mitchell, U.H. Effect of Whole Body Vibration on Skin Blood Flow and Nitric Oxide Production. J. Diabetes Sci. Technol. 2014, 8, 889-894. [CrossRef] [PubMed]

34. Arashi, M.; Sugama, J.; Sanada, H.; Konya, C.; Okuwa, M.; Nakagami, G.; Inoue, A.; Tabata, K. Vibration therapy accelerates healing of Stage I pressure ulcers in older adult patients. Adv. Ski. Wound Care 2010, 23, 321-327. [CrossRef] [PubMed]

35. Okuwa, M.; Nakagami, G.; Sugama, J.; Sanada, H.; Konya, C. Acute effect of leg vibration on cutaneous microcirculation and macrocirculation in patients during hemodialysis. Jpn. J. Nurs. Art Sci. 2009, 8, 56-62.

36. Ichioka, S.; Yokogawa, H.; Nakagami, G.; Sekiya, N.; Sanada, H. In vivo analysis of skin microcirculation and the role of nitric oxide during vibration. Ostomy Wound Manag. 2011, 57, 40-47.

37. Sato, K.; Kang, W.H.; Saga, K.; Sato, K.T. Biology of sweat glands and their disorders. I. Normal sweat gland function. J. Am. Acad. Dermatol. 1989, 20,537-563. [CrossRef]

38. Leveque, J.L. Measurement of transepidermal water loss. Cutan. Investig. Health Dis. Non-Invasive Methods Instrum. 1989, 135-151.

39. van Jansen Rensburg, S.; Franken, A.; Du Plessis, J.L. Measurement of transepidermal water loss, stratum corneum hydration and skin surface $\mathrm{pH}$ in occupational settings: A review. Skin Res. Technol. 2019, 25, 595-605. [CrossRef]

40. Du Plessis, J.; Stefaniak, A.; Eloff, F.; John, S.; Agner, T.; Chou, T.C.; Nixon, R.; Steiner, M.; Franken, A.; Kudla, I.; et al. International guidelines for the in vivo assessment of skin properties in non-clinical settings: Part 2. transepidermal water loss and skin hydration. Skin Res. Technol. 2013, 19, 265-278. [CrossRef]

41. Alexander, H.; Brown, S.; Danby, S.; Flohr, C. Research Techniques Made Simple: Transepidermal Water Loss Measurement as a Research Tool. J. Investig. Dermatol. 2019, 138, 2295-2300.e1. [CrossRef]

42. Ali, S.M.; Yosipovitch, G. Skin pH: From basic science to basic skin care. Acta Derm.-Venereol. 2013, 93, 261-267. [CrossRef] [PubMed]

43. Rippke, F.; Berardesca, E.; Weber, T.M. PH and Microbial Infections. Curr. Probl. Dermatol. 2018, 54, 87-94. [PubMed]

44. Miyaji, A.; Sugimori, K.; Hayashi, N. Short- and long-term effects of using a facial massage roller on facial skin blood flow and vascular reactivity. Complement. Ther. Med. 2018, 41, 271-276. [CrossRef] [PubMed]

45. Danby, S.G.; AlEnezi, T.; Sultan, A.; Lavender, T.; Chittock, J.; Brown, K.; Cork, M.J. Effect of Olive and Sunflower Seed Oil on the Adult Skin Barrier: Implications for Neonatal Skin Care. Pediatr. Dermatol. 2013, 30, 42-50. Available online: https:/ / onlinelibrary.wiley.com/doi/10.1111/j.1525-1470.2012.01865.x (accessed on 3 December 2021). [CrossRef] 